\title{
Content of heavy metals and arsenic in soils near Sharra landfill (Tirana, Albania)
}

\author{
Natalia Chernykh*, Yulia Baeva and Anamaria Thoma \\ Peoples Friendship University of Russia (RUDN University), Faculty of Ecology, 6 Miklukho- \\ Maklaya Street, Moscow, 117198, Russian Federation
}

\begin{abstract}
The paper presents the results of a comparative assessment of the degree of pollution of subtropical brown soils with a number of heavy metals (V, Mo, Co) and arsenic in the zone of influence of solid municipal waste landfill "Sharra". The landfill is located about $7 \mathrm{~km}$ southwest of the center of Tirana. Until the early 1990s it was used mainly for the disposal of industrial waste, subsequently it became an uncontrolled open dump and is now the dumping area for all waste of the capital city of the Republic of Albania. Total metal and As contents were determined by inductively coupled plasma atomic emission spectrometry in samples from 14 sites at different distances from the landfill body. Concentrations of V - in 1.2-1.3 times, Mo - more than in 2.2-4.4 times, Co - in 1.2-1.5 times and As - more than in 3.4 times were exceeded background concentration. It was also revealed 1.7 times higher than the established normative value for As in soils. The obtained results confirm the hypothesis about the negative impact of the Sharra landfill on the adjacent territories.
\end{abstract}

\section{Introduction}

The rapid growth of the population and, as a consequence, a significant increase in the volume of solid municipal waste in the city of Tirana has necessitated the solution of problems related to environmental pollution. The volume of accumulated waste in the landfill increased by 95,000 tons between 2016 and 2019 and has now reached 365,000 tons [1-2]. The environmental hazard of this increase in waste is exacerbated by the fact that the landfill is located in the catchment area of the Erzen River in the immediate vicinity of the Mediterranean Sea [3-6]. The landfill is also intensively affected by the soil of the territories adjacent to it. At the same time, municipal waste often serves as a source of contamination of the soil cover with many chemical elements, including heavy metals and arsenic [7-10].

\footnotetext{
* Corresponding author: chernykh-na@rudn.ru
} 


\section{Objects and methods}

The object of the research is the soil cover of the territory adjacent to the landfill Sharra (Albania). The landfill is located about $7 \mathrm{~km}$ south-west of Tirana city center and about 400-500 m south-west of Sharra village.

Until the early 1990s, the area near the village of Sharra was used mainly for industrial waste. Later it became an uncontrolled open landfill, where all the waste of the city of Tirana was dumped. In 2008, a project was developed to create a landfill in accordance with European standards, which included expanding the boundaries of the existing landfill at that time. In 2015, as part of the new project, a station for the collection and sorting of solid municipal waste was built on the landfill site, and in 2017 it was decided to create an entire complex for the disposal of municipal waste, including a landfill, a waste processing plant and a municipal wastewater treatment plant $[3,11]$. The composition of waste disposed at Sharra landfill is shown in Figure 1.

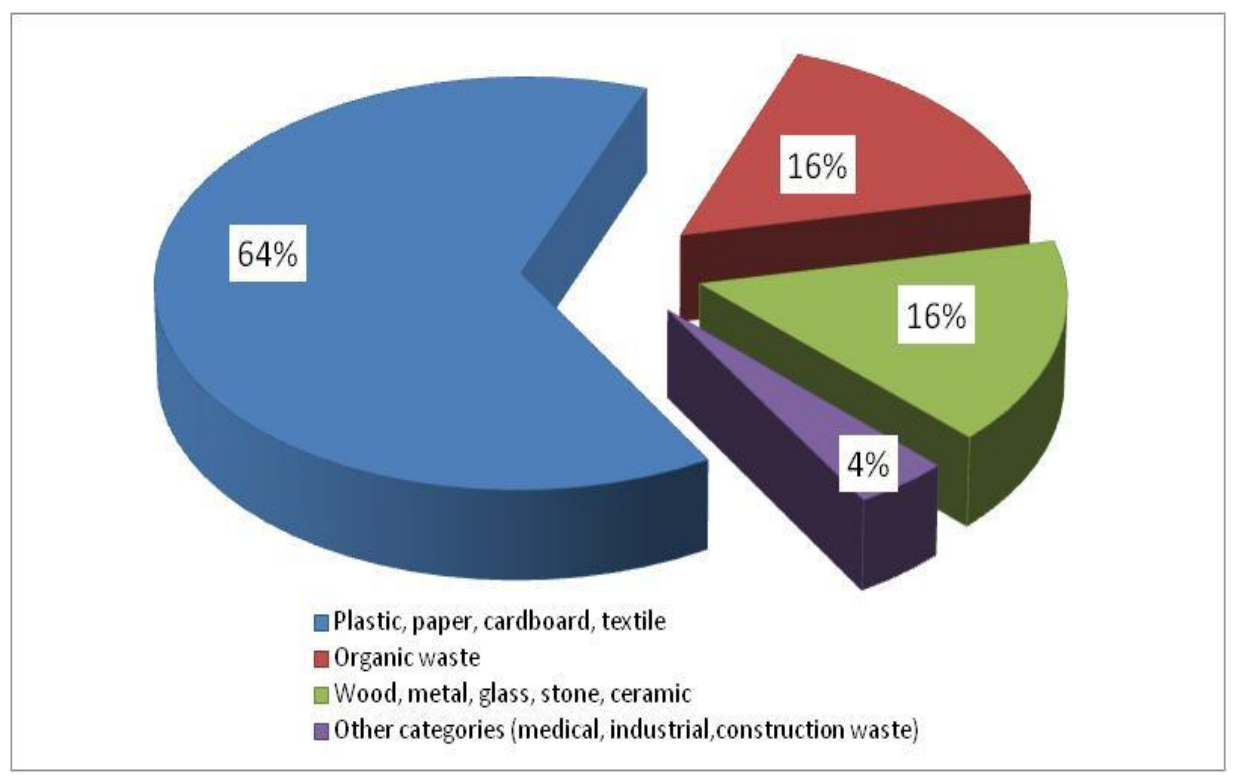

Fig. 1. The composition of waste disposed at Sharra landfill.

The soil cover of the study area is represented by subtropical brown soils, occupying lowlands, river valleys and mountainous terrain elements up to 300-600 m high, formed under Mediterranean climate conditions. Soil-forming rocks are eluvial-deluvial carbonate loams. Soil acidity is close to neutral, humus content is about $4.5 \%$, and cation exchange capacity (CEC) is $29-32 \mathrm{mg}$-eq/100 g.

Fourteen sites were selected for sampling, with three 100x100 m sites located at each site (Figure 2): 12 sites within the range of the landfill, one site - "conditionally background" - at a distance of $0.8 \mathrm{~km}$ from it and one site - background - at a distance of $1.5 \mathrm{~km}$ from the landfill. The "conditionally background" site (No. 13) is located in an area with similar landforms, geological structure, and soil cover. The background site (No. 14) is characterized by soil and geological conditions as close to the territory of the polygon as possible. 


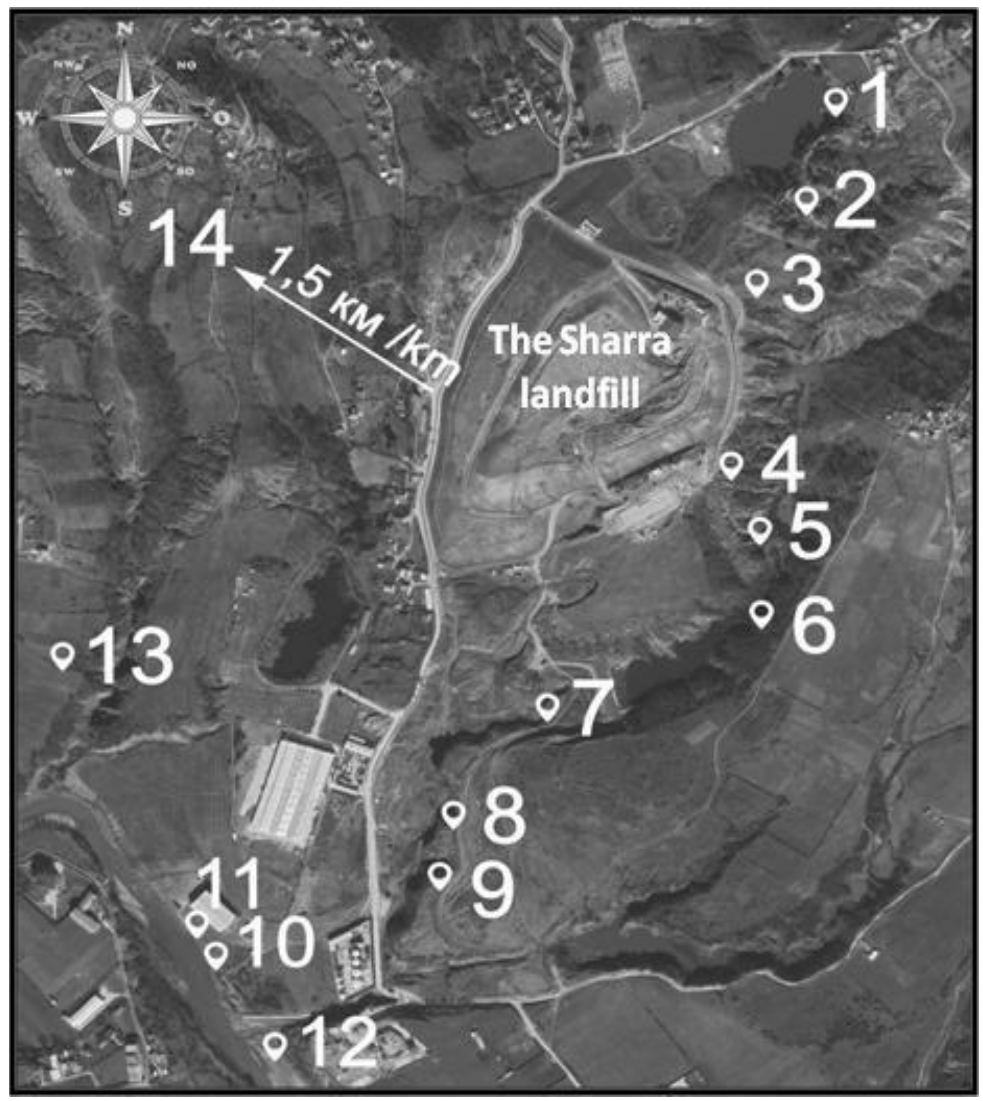

Fig. 2. Layout of soil sampling plots.

Soil samples were taken from a depth of 0-20 cm, taking into account the terrain features in accordance with the existing methodological recommendations [12]. A combined mixed soil sample from each site was formed from five point samples taken by the envelope method.

Quantitative chemical analysis of soil samples was carried out at the chemical analysis laboratory of the Institute of Geology of Ore Deposits, Petrography, Mineralogy and Geochemistry (IGEM RAS). The elemental composition (total content) of soils was determined by the inductively coupled plasma atomic emission spectrometry method [13, 14].

All assays were done in triplicate. The mean values and standard errors (SE) are presented in the tables and diagrams. All statistical analyses were performed with MS Excel 2007 (Microsoft Office XP) using the $\alpha=0.05$ level of significance.

\section{Results and discussion}

Experimental data on the content of heavy metals and arsenic in soils near the Sharra landfill are shown in the Figures 3-6. 


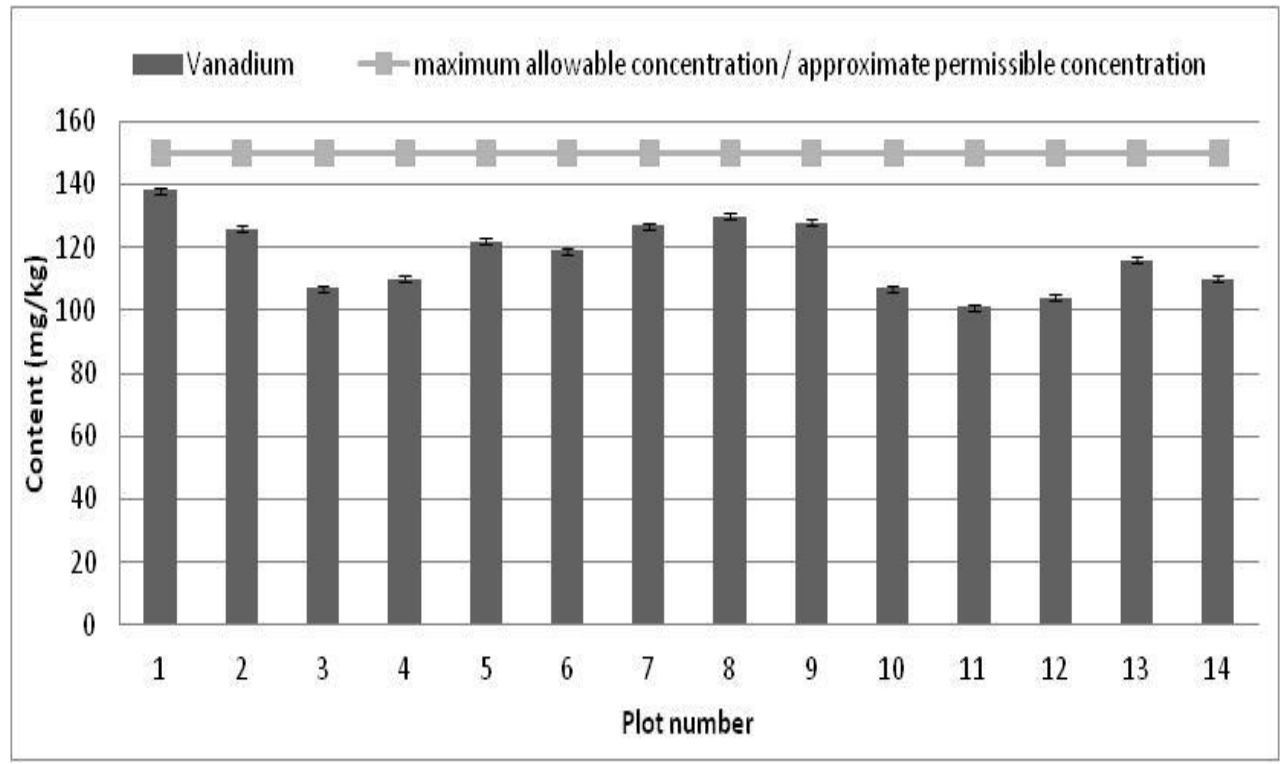

Fig. 3. Vanadium content in soils. MACs and APCs are given for the Russian Federation $[15,16]$, since Albania does not currently have.

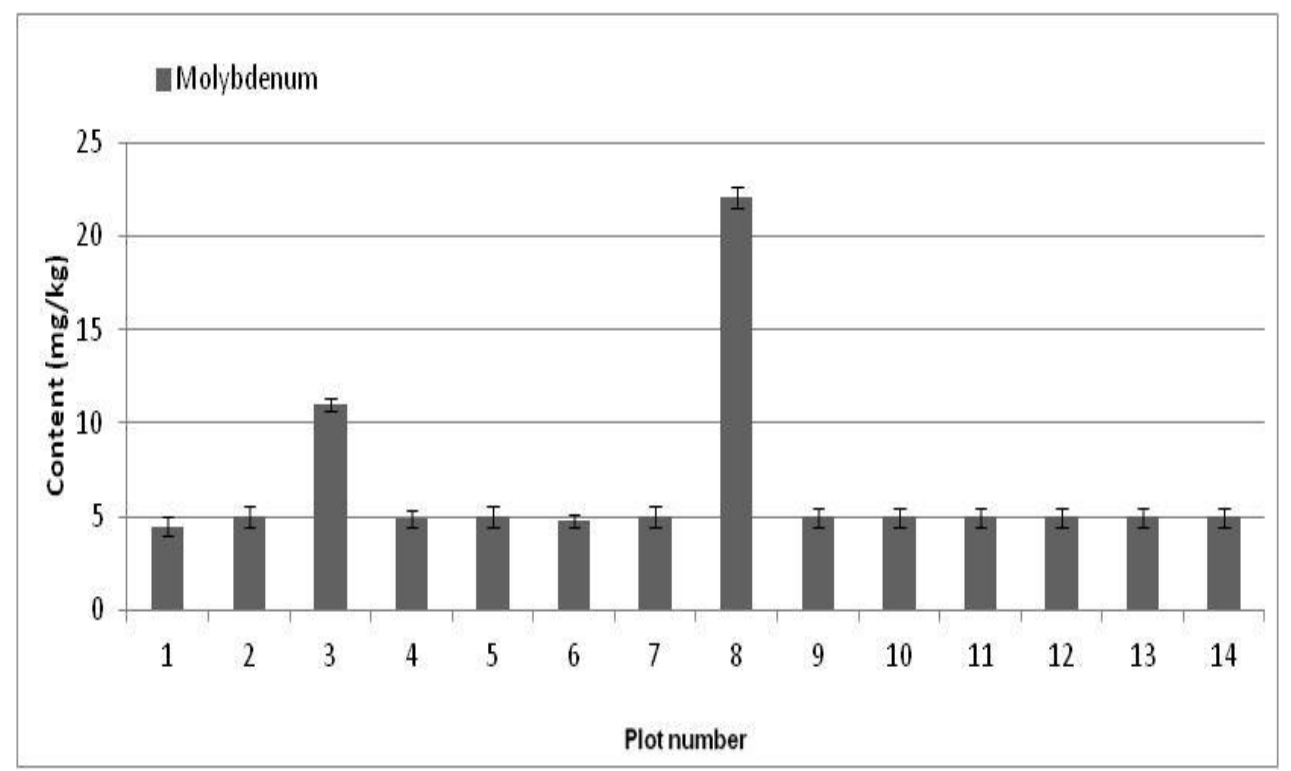

Fig. 4. Molybdenum content in soil samples. MACs and AACs are not currently established.

During the studies the following exceedances of background concentrations of elements were recorded: $\mathrm{V}$ - in 1.2-1.3 times (at sites №№ 1, 2, 7-9), Mo - more than in 2.2-4.4 times (at sites № 3, 8), Co - in 1.2-1.5 times (at sites № 1, 6-8), As - more than in 3.4 (at site № $11)$. 


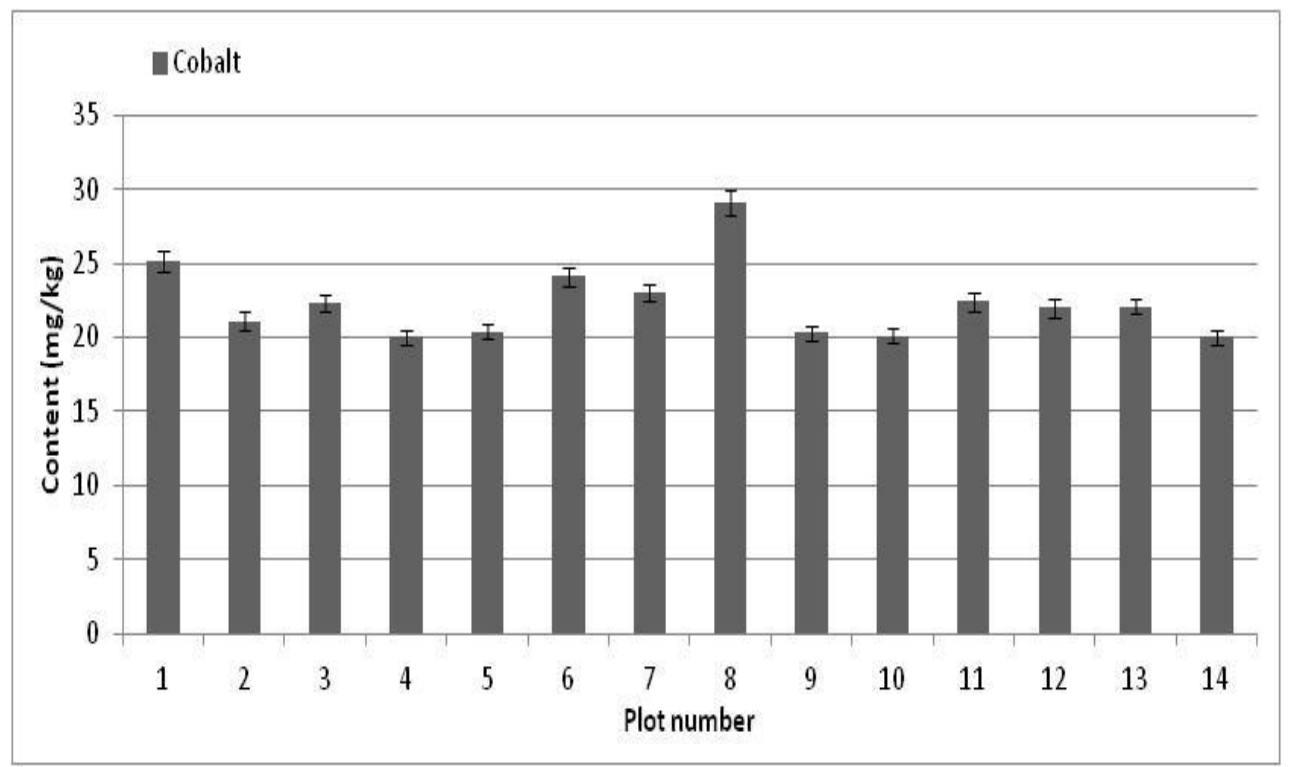

Fig. 5. Cobalt content in soil samples. MACs and APCs are not currently established.

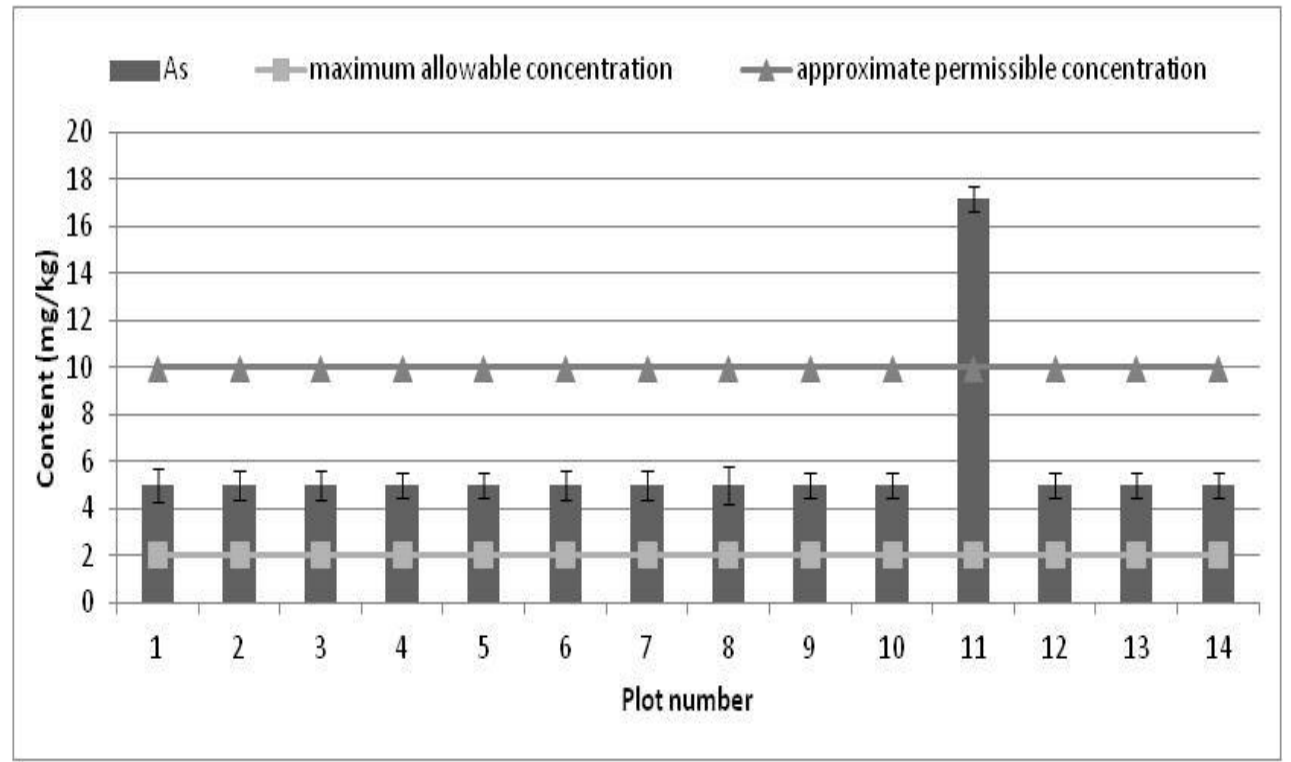

Fig. 6. Arsenic content in soils. MACs and AACs are given for the Russian Federation $[15,16]$, since Albania does not currently have.

For As on a site № 11 excess not only background level of concentration in soil, but also the established standard value of approximate permissible concentration in 1,7 times is revealed.

Despite the above-mentioned exceedances of normative values, soils near the Sharra landfill can be classified as soils with low and medium levels of contamination, as they correspond to the category of acceptable levels of contamination according to the total indicator of contamination. 


\section{Conclusions}

The results obtained allow us to conclude that all the studied elements are characterized by high variability in the content in the upper soil horizon, which is not characteristic of natural brown soils, indicating a technogenic entry of elements into the soil from the landfill. At the same time, the main reason for contamination of the soil cover with heavy metals and arsenic is probably the presence of industrial waste buried back in the $70-80$ s of the last century in the body of the Sharra landfill.

\section{References}

1. Sustainable development strategy of the Municipality of Tirana $2018-2022$. General directorate of strategic planning and human resources Municipality of Tirana

2. The open data portal of the Municipality of Tirana. URL: https://opendata.tirana.al/

3. Regional Development Concept for the Region of Tirana. URL: http://www.qarkutirane.gov.al/

4. A. Bani, F. Brahushi, E. Cela, S. Mustafaj, E. Jojic, Albanian J. Agric. Sci., 10, 1, 3138 (2011)

5. E. Cela, A. Bani, A. Molla, D. Gjeci, F. Brahushi, BALWOIS 2012, 1-5, (2012)

6. O. Manastirliu, P. Lazo, IJEES, 2, 3, 217-222, (2012)

7. K. Gjoka, T. Shehi, F. Nepravishta, J. Environ. Sci. Eng., B 1, 1239-1244, (2012)

8. V. N. Eremin, P. D. Pavlov, M. V. Reshetnikov, A. S. Sheshnev, Eng. Geol. World, 2, 50-61, (2016)

9. N. O. Milyutina, N. G. Osmolovskaya, N. A. Politaeva, V. V. Kurilenko, Environ. Geosci. J., 3, 55-63, (2020)

10. N. A. Chernykh, A. Thoma, Yu .I. Baeva, SGEM 2020, 20 (5.1), 123-130, (2020)

11. M. Alcani, A. Dorri, A. Hoxha, Int. J. Sci. Technol. Manage., 4, 1, 16, (2015)

12. GOST 17.4.4.02-2017. Nature protection. Soils. Methods for sampling and preparation of soil for chemical, bacteriological, helmintological analysis. International standard

13. NSAM 155-HS-1, (2015)

14. NSAM 357-X, (2015)

15. GN 2.1.7.2041-06 Hygienic Standards. Maximum allowable concentrations (MAC) of chemical substances in soil (2006)

16. GN 2.1.7.2511-09 Hygienic Standards Approximate permissible concentrations (APC) of Chemicals in Soil (2009) 